\title{
Diffusion in gadolinium doped ceria thin films: a combined Monte Carlo and molecular dynamics study
}

\author{
John A. Purton
}

\section{Published version information}

Citation: JA Purton. "Diffusion in gadolinium doped ceria thin films: a combined Monte Carlo and molecular dynamics study." Physical Chemistry Chemical Physics, vol. 21, no. 19 (2019): 9802-9809.

DOI: https://doi.org/10.1039/C8CP07136E

This version is made available in accordance with publisher policies. Please cite only the published version using the reference above. This is the citation assigned by the publisher at the time of issuing the AAM/APV. Please check the publisher's website for any updates. 
Diffusion in Gadolinium doped Ceria thin films: A combined Monte Carlo and Molecular Dynamics Study.

John A Purton ${ }^{\mathrm{a}^{*}}$

a Scientific Computing Department, Daresbury Laboratory, Keckwick Lane, Warrington, UK. Tel: +44 1925 603785; E-mail: john.purton@stfc.ac.uk.

\section{Abstract}

The mobility of oxygen ions at surfaces and interfaces in solid oxide fuel materials is controversial. Experiments are complex and conflicting results for grain boundary and surface $\mathrm{O}^{2-}$ diffusion have been obtained. Thus it is not clear on the conditions necessary to optimise the $\mathrm{O}^{2-}$ diffusion during the manufacturing process. To aid the interpretation of experimental results combined Monte Carlo and molecular dynamics simulations were applied to model thin films of $\mathrm{CeO}_{2}$ on binary oxide substrates. The objectives of this work is to determine the rôle of both tensile lattice strain and segregation on the calculated diffusion coefficients. The distribution of $\mathrm{Gd}^{3+}$ and $\mathrm{O}^{2-}$ ions has been interpreted as evidence for the formation of a space charge layer at both the interface and surface. The space charge layer impacts the calculated diffusion coefficients at the thin film surface. Moderate tensile strain in the $\mathrm{CeO}_{2}$ thin film has little influence on the segregation of $\mathrm{Gd}^{3+}$ ions. 


\section{Introduction}

An increasing desire for low $\mathrm{CO}_{2}$ emission technologies has motivated substantial research into novel materials for applications such as batteries, thermoelectrics and solid oxide fuel cells (SOFCS). The most desirable properties for materials to act as the electrolyte in SOFCS are high oxygen ion conductivity, low electronic conductivity and high thermal stability. ${ }^{1,2,3}$ Yttrium doped zirconia (YSZ) is often employed within SOFCS due to its chemical stability at high temperatures. However, the ionic conductivity is relatively low and high temperatures $(1000-1200 \mathrm{~K})$ are required. These high temperatures result in a number of problems associated with the use of YSZ electrolyte devices (e.g. corrosion). To overcome these problems there has been considerable research to develop alternate ionic conducting materials that can operate at lower temperatures. Gadolinium doped ceria (GDC) and other rare earth doped electrolytes have high oxygen mobility and exhibit great potential. In these compounds, e.g. GDC, for every two $\mathrm{Gd}^{3+}$ dopants introduced, an oxygen vacancy is created (equation 1) and it is these vacancies that allow oxygen ions to migrate more easily through the material.

$$
\mathrm{Gd}_{2} \mathrm{O}_{3} \stackrel{\mathrm{CeO}_{2}}{\longrightarrow} 2 \mathrm{Gd}_{\mathrm{Ce}}^{\prime}+\mathrm{V}_{\mathrm{O}}^{*}+3 \mathrm{O}_{\mathrm{O}}^{\mathrm{x}}
$$

The ionic conductivity is considerably more complex than equation 1 would suggest and the experimental conductivity of GDC is not a simple function of the dopant concentration, but passes through a maximum at approximately 20 to $30 \% \mathrm{Gd}$. Above this the conductivity starts to decrease, which has been interpreted in terms of the formation of associated clusters of the dopant cations and the oxygen vacancies. ${ }^{1}$

The experimental conductivity is further complicated by the presence of grain boundaries ${ }^{4}$ and that it is dependent on the thermal history of the sample. ${ }^{5}$ To improve the thermodynamic stability of GDC and the lifetime of the end device researchers have explored the relationship between the ionic conductivity and microstructure. Optimisation of the conductivity has stimulated the investigation of complex interfaces and thin films. This body of work has been inspired by the reports of an increase of 8 orders of magnitude in the conductivity at YSZ|STO interfaces. ${ }^{6}$ However, more recent experiments, including those on GDC interfaces, have only demonstrated a 2-3 orders of magnitude increase. ${ }^{7,8,9,10}$ The increase in conductivity has been attributed to a tensile strain at the interface that 
distorts the structure of the thin film and thus reduce the activation energy for $\mathrm{O}^{2-}$ migration. In addition, a number of theoretical studies have been published using static simulations $s^{11,12}$ and molecular dynamics ${ }^{13,14,15}$ to determine the relationship between strain and ionic conductivity at the atomic scale.

More recently experiments have been designed to use lattice strain as a route to modify the degradation effects in functional oxides for high-temperature electrochemical devices. Surface science experiments have been employed to examine the influence of surface strain on the degree of segregation of dopant cations by deposition of thin films on to a range of substrates. ${ }^{16,17}$ These experiments are extremely complex and it is often difficult to ascertain whether thermodynamic equilibrium has been achieved. For example, both positive and negative values have been obtained for the enthalpy of segregation in yttrium stabilised zirconia and gadolinium doped ceria. ${ }^{16,18,19}$

This paper concentrates on the rôle of strain on segregation and $\mathrm{O}^{2-}$ diffusion in thin films using a combination of hybrid Monte Carlo and molecular dynamics simulations. Unlike previous simulations ${ }^{13,14,15}$, the distribution of cations and anions is determined within the simulation and the simulation cell was designed to model experiments. For this purpose we have simulated gadolinium doped $\mathrm{CeO}_{2}$ on binary oxide substrates. This material was chosen as it is of technological interest in the field of SOFCs. The oxides employed in this study were $\mathrm{MgO}, \mathrm{FeO}$ and $\mathrm{MnO}$ and the surface was the $\{001\}$ which is the most stable surface. ${ }^{20}$ The lattice parameters of these oxides are $4.21,4.33$ and $4.43 \AA$ respectively which allows the interfaces to be constructed so as to give a range of size mismatch between the substrate and the ceria thin film. The sole purpose of using the different oxides is to control the quantity of strain placed on the thin film. The degree of mismatch was determined from the calculated lattice parameters and ranged from less than $1 \%$ to approximately $5 \%$ (the magnitudes are given in table 1 ). The excess volume of mixing of $\mathrm{CeO}_{2}$ and $\mathrm{Gd}_{2} \mathrm{O}_{3}$ is small (approximately $0.02 \AA$ for $\mathrm{Gd}_{0.3} \mathrm{Ce}_{0.7} \mathrm{O}_{1.85}$ using the potential model described below) and the Gd concentration has little impact on the lattice mismatch between the substrate and thin film. Unfortunately, limitations in computer power prevented construction of simulation cells with the same degree of lattice vector mismatch in all directions. Despite this the difference in degree of mismatch between directions is small. 


\section{Computational Method}

\subsection{Construction of the simulation cell.}

The thin film was constructed in a similar manner to previous atomistic simulations. ${ }^{21,22}$ There have been numerous computational (for example, references 23 and 24) studies on the structure and stability of the low-index surfaces of $\mathrm{CeO}_{2}$ and are discussed in in detail in reference 20 . The general consensus is that stability of the surfaces decreases in the order $\{111\}>\{110\}>\{100\}$. The $\mathrm{CeO}_{2}\{111\}$ surface is a Tasker Type 2 surface ${ }^{25}$ in which each plane is charged but the repeat unit (in this case consisting of three planes, 1 cation plane and 2 anion planes) results in no net dipole moment perpendicular to the surface (figure 1). The nomenclature used in reference 26 is employed to describe the oxygen layers at the surface as surface, first subsurface and second subsurface. A similar terminology is used to describe the oxygen layers at the interface, i.e. interface, first sub-interface and second subinterface (see figure 1). In addition, both experiment and theory have identified that the most stable surface is terminated by the oxygen plane. Thus the $\mathrm{CeO}_{2}$ slab was created with oxygen ions on both terminations. Moreover, this surface was used in previous calculations and we can make comparisons with these results. ${ }^{14}$

The simulation cell was constructed in an identical procedure to those employed in the MIDAS and METADISE codes. ${ }^{27}$ The cell is repeated in two-dimensions (in most simulation period boundary conditions are applied in three dimensions and a vacuum region applied to prevent the interaction of ions) and the substrate is split into two regions; region 1 and region 2 . The first region is the portion that is adjacent to the thin film and is allowed to move during molecular dynamics or energy minimisation. The second region that represents the bulk material serves to complete the summations in the potential energy and is held fixed in all simulations. The substrate is made up of 10 unit cells in depth (4 unit cells for region 1 and 6 for region 2)(for the purpose of this paper a unit cell of the binary oxides contains 8 atoms). The thin film of $\mathrm{CeO}_{2}$ was constructed by placing a slab, cut to expose the $\{111\}$ surface, directly onto the surface of the binary oxide substrate. Subsequently, for each $\mathrm{Gd}_{\mathrm{x}} \mathrm{Ce}_{1-\mathrm{x}} \mathrm{O}_{2-\mathrm{x} / 2}$ composition $\left(x=0.1,0.2\right.$ and 0.3 ) the appropriate number of $\mathrm{Ce}^{4+}$ ions were replaced with $\mathrm{Gd}^{3+}$ ions and $\mathrm{O}^{2-}$ ions deleted. Each layer of the $\mathrm{CeO}_{2}$ thin film has 288 potential sites. 


\subsection{Monte Carlo}

The properties of cation defects in solid state ionic materials are often investigated using either supercell or point defect calculations. ${ }^{28}$ However, these methods are not readily extended to disordered systems containing a finite impurity or defect content, thereby restricting simulations to end-member compounds and excluding studies of many naturally occurring minerals and ceramics of industrial importance. In addition, standard Monte Carlo and molecular dynamics simulations are unable to overcome kinetic energy barriers to sufficiently sample all necessary configurations. Thus in previous papers we have described $M C$ methods that exchange cation positions in order to sample multiple configurations and calculate the thermodynamic and solubility limits of ionic materials. ${ }^{29,30,31}$ The exchange of positions is accepted or rejected by comparing the energy of the final and starting configurations and using the standard Metropolis algorithm. ${ }^{32}$ The Metropolis approach requires that a trial move from the original state $(o)$ to a new state $(n)$ is accepted with the probability:

$$
P_{(o \rightarrow n)}=\exp \left\{-\beta\left[U_{n}-U_{o}\right]\right\}
$$

where $U_{n}$ and $U_{o}$ are the energies of the new and original states and $\beta$ is $1 / k T$. However, even with MC swaps the sampling of configurations will be very inefficient when the difference in energy is very large and it is necessary to allow the ions to adjust their positions in order to minimise the energy difference. Each configuration was relaxed using the damped-MD fast inertial relaxation engine, FIRE, algorithm ${ }^{33,34,35}$ so that the energies were converged to within $1.0 \times 10^{-5} \mathrm{eV}$. An advantage of the FIRE approach is that it is easily parallelisable. In these simulations we swapped the positions of the $\mathrm{Gd}^{3+}$ and $\mathrm{Ce}^{4+}$ ions. The $\mathrm{O}^{2-}$ ion positions were allowed to relax, however, to ensure that the $\mathrm{O}^{2-}$ ions adapted to the cation environment an additional molecular dynamics step was introduced. Thus after every 10,000 Monte Carlo cycles a short, 10,000 step, molecular dynamics, MD, simulation was undertaken. The $\mathrm{O}^{2-}$ ions were not observed to exchange position with the substrate although this behaviour was not prevented. The internal energy and structural data were monitored over a period of 150,000 cycles, prior to which an equilibration period of 150,000 cycles was undertaken.

2.2 Molecular Dynamics and calculation of diffusivity. 
The diffusivity of the $\mathrm{O}^{2}$ ions within the thin films were calculated using molecular dynamics simulations. ${ }^{36}$ The MD simulations were undertaken at the appropriate temperature using the NVE ensemble using a $1 \mathrm{fs}$ time step. Three configurations taken from the MC calculations were used as starting points for three separate MD simulations and the average of these used to determine the property of interest. Each MD calculation consisted of a 100 picosecond equilibration phase followed by a further 900 picosecond phase, during which the atomic positions were collected. The mean squared displacements, MSD, are obtained from the atomic trajectories.

$$
\left\langle r_{i}^{2}(t)\right\rangle=\frac{1}{N} \sum_{i=1}^{N}\left[r_{i}(t)-r_{i}(0)\right]^{2}
$$

The oxygen diffusion coefficient, $D$, was calculated from the mean squared displacements using equation.

$$
\left\langle r_{i}^{2}(t)\right\rangle=2 d D t(t \rightarrow \infty)
$$

where $d$ is the dimensionality of the MSD calculation. From the Arrhenius behaviour of the jump-frequency one can extract a vacancy migration energy or an average activation energy for $\mathrm{O}^{2-}$ migration,

$$
D=D_{0} \exp \left(\frac{-E_{a}}{k T}\right)
$$

where $E_{a}$ is the activation energy for diffusion.

\subsection{Potential model}

A rigid ion model was used for both the Monte Carlo and molecular dynamics simulations and Buckingham potentials (equation 6) were employed to model the atomic interactions.

$$
V_{i j}=A \exp \left(-\frac{r_{i j}}{\rho}\right)-\frac{C}{r_{i j}^{6}}+\frac{z_{i} z_{j} e^{2}}{r_{i j}}
$$

$A, \rho$ and $C$ are constants, $r_{i j}$ is the distance between ions of type $i$ and $j$, and $z_{i}$ and $z_{j}$ are the charges of species $i$ and $j$ respectively. The potential parameter set is from reference 37 (see table 1 in the supplementary information) and each ion was assigned an integer charge, i.e. +2 for $\mathrm{Mg} / \mathrm{Fe} / \mathrm{Mn},+3$ for $\mathrm{Gd},+4$ for $\mathrm{Ce}$ and -2 for $\mathrm{O}$. The parameters for the $\mathrm{O}^{2-}$ within the thin film and substrate are identical. The evaluation of the Coulomb interaction requires special consideration as the simulation requires repetitively relaxing approximately 15000 
ions in a total cell size of approximately 30000 particles. Recently several alternatives have been proposed that allow the electrostatic contribution to the total energy to be calculated simply as a pairwise interaction. ${ }^{38,39}$ Fennell and Gezelter have proposed the use of a damped and shifted potential, $U_{F G}$,

$U_{F G}=q_{i} q_{j}\left[\frac{\operatorname{erfc}(\propto r)}{r}-\frac{\operatorname{erfc}\left(\propto R_{c}\right)}{R_{c}}+\left(\frac{\operatorname{erfc}\left(\propto R_{c}\right)}{R_{c}^{2}}+\frac{2 \propto}{\pi^{\frac{1}{2}}} \frac{\exp \left(-\alpha^{2} R_{c}^{2}\right)}{R_{c}}\right)\left(r-R_{c}\right)\right], r \leq R_{c}$

where $\alpha$ is a damping parameter. The damping function serves to accelerate the convergence of the Coulomb energy to the correct energy as the pairwise interaction cutoff $R_{c}$ distance is increased. ${ }^{40,41}$ The advent of these methods significantly speeds up the calculation of the Coulomb interactions as it permits the computation of the electrostatic terms in the same section of the program as the non-bonded pair interactions. A potential cutoff of $20 \AA$ was used for both the Coulombic and non-Coulombic interactions.

\section{Results.}

\subsection{Thin Film Structure}

Snapshot taken from the Monte Carlo simulation are presented in figures 2 and 3 . The thin films on both the $\mathrm{MgO}$ (figure 2) and FeO (figure 1 in the supplementary information) substrates form a semi-coherent interface at all compositions and temperatures. In contrast, the thin films grown on the $\mathrm{MnO}$ substrate (figure 3) contain dislocations that results from the degree of strain placed on the thin film. The integrity of the thin films are also reflected in the $\mathrm{Gd}^{3+}$ distribution within the thin film. The $\mathrm{Gd}^{3+}$ ions are not randomly distributed, but form linear chains. The number of $\mathrm{Gd}^{3+}$ ions as a function of the distance from the interface is displayed in figure 4. For the $\mathrm{MgO}$ and $\mathrm{FeO}$ substrates it is possible to identify the ions belonging to distinct layers and to express the $\mathrm{Gd}^{3+}$ fraction for any layer (e.g. the surface and interface) as:

$$
c_{G d}=\frac{N_{G d}}{\left(N_{G d}+N_{C e}\right)}
$$

where $N_{G d}$ and $N_{C e}$ are the number of $\mathrm{Gd}^{3+}$ and $\mathrm{Ce}^{4+}$ ions within a specific layer. The calculated values of $c_{G d}$ indicate that there is significant segregation of the dopant cations to both the interface and the surface (Table 2). Surprisingly the degree of segregation is greatest at the interface. An estimate of the segregation energy $\left(E_{\text {seg }}=E_{\text {surface }}-E_{\text {bulk }}\right)$ 
can be determined by manually swapping the position of a $\mathrm{Gd}^{3+}$ ion at the surface or interface with that of $\mathrm{C} \mathrm{Ce}^{4+}$ ion at the centre of the thin film. For the $\mathrm{MgO}$ and $\mathrm{FeO}$ substrates the $\mathrm{Gd}^{3+}$ segregation energy is approximately -0.8 and -0.6 for the interface and surface respectively (a negative value of $E_{\text {seg }}$ indicates a more favourable location for the $\mathrm{Gd}^{3+}$ ions). The segregation energy for the $\mathrm{MnO}$ substrate is approximately $+0.2 \mathrm{eV}$. The fraction of $\mathrm{Gd}^{3+}$ ions at the surface and interface is only slightly greater for the $\mathrm{MgO}$ substrate when compared to that of the $\mathrm{FeO}$ substrate. In addition, the amount of segregation is independent of temperature as the segregation energies are large. ${ }^{42}$ In contrast, the $\mathrm{Gd}^{3+}$ ions within the $\mathrm{MnO}$ supported film do not exhibit significant segregation and the distinct layers of ions cannot be determined (figure 4). This indicates that a tensile surface strain of a few percent has little influence on the segregation of dopant cations in $\mathrm{CeO}_{2}$ and only becomes significant when the structure of the thin film starts to deteriorate and alternate sites become energetically favourable (e.g. close to dislocations).

The number of $\mathrm{O}^{2-}$ ions within each layer can easily be determined from their positions relative to the interface. The total number of oxygen ions within the thin film is constant and oxygen vacancy concentration within a layer is obtained by subtracting the number of oxygen ions from the number of available oxygen sites. The $\mathrm{CeO}_{2}$ thin films supported on $\mathrm{MgO}$ and $\mathrm{FeO}$ substrates have similar characteristics within their oxygen (vacancy) depth profiles (figure 5). In all calculations both the surface and interface oxygen layers are composed of $\mathrm{O}^{2-}$ ions and contain very few vacant oxygen positions (this is still observed in simulations where the $\mathrm{Gd}^{3+}$ ions are distributed randomly throughout the thin film). The next layer two oxygen layers away from the both the surface and interface are have an increased vacancy concentration. A number of computational studies have indicated that the subsurface layer is the most energetically favourable position for the oxygen vacancies. ${ }^{26,35,42}$ This is not observed for simulations in which the $\mathrm{Gd}^{3+}$ ions are randomly distributed and the number of $\mathrm{O}^{2-}$ ions and vacancies in the sub-interface and sub-surface layers is similar to the remainder of the thin film. The central portion of the thin film has vacancies at a much lower level. The profile of oxygen vacancies is consistent with the space charge models. ${ }^{43,44,45}$ Interestingly, the number of $\mathrm{O}^{2-}$ vacancies is less at the interface than the surface despite the level of $\mathrm{Gd}^{3+}$ ion segregation at the interface being greater than that 
at the surface. The segregation energies for oxygen ion vacancies at the subinterface and subsurface layers is approximately -0.2 and $-0.4 \mathrm{eV}$ respectively.

\subsection{Diffusion}

The mean squared displacement for oxygen ions for all the models was observed to increase linearly with time and the slope of $\left\langle r_{i}^{2}(t)\right\rangle$ is found to be constant (this gives the diffusion coefficient $(D)$, see supplementary information). The oxide ion diffusion coefficients for the entire thin film are presented in table 3 for all three substrates and decreases with increasing $\mathrm{Gd}^{3+}$ concentration. This behaviour is in contrast to that observed for bulk $\mathrm{CeO}_{2}$ where the conductivity increases to a maximum at approximately $x=0.2$ to $x=0.3$. The difference is even more pronounced if the $\mathrm{Gd}^{3+}$ fraction at the centre of the thin film is employed for comparison (see table 2). In addition, the value of $D$ obtained using configurations produced by the Monte Carlo calculations is similar to those determined in which $\mathrm{Gd}^{3+}$ are randomly distributed. This is in contrast to calculations performed on the bulk material where ordering of the $\mathrm{Gd}^{3+}$ ions into nanodomains during the Monte Carlo simulations results in a reduction of the oxygen ion conductivity. ${ }^{35,46}$ The greatest value of diffusion coefficients is for the FeO substrate (it is approximately 1.5 times greater than for the other substrates) and for the $\mathrm{MnO}$ substrate there is a similar value to that of $\mathrm{MgO}$ despite the increased spacing and the formation of dislocations in the thin film structure. The calculated activation energies for the three substrates are given in table 4 (Arrhenius plots used to obtain these results are given in the supplementary information) and the calculated values are in good agreement with those obtained from experiments (these range from 0.6 to $1.2 \mathrm{eV})^{47,48,49}$ although direct comparison with experiment is difficult as the thickness and area of the films in this study are significantly reduced. The activation energies tend to increase with the $\mathrm{Gd}^{3+}$ content of the thin film and is consistent with total $\mathrm{O}^{2-}$ diffusion coefficients.

In figure 6 the diffusion coefficients for $\mathrm{O}^{2-}$ diffusion parallel to the surface, $D_{2 d}$, are presented as a function of distance above the interface (using equation 4 the dimensionality of the calculation, $d$, is set to 2 ). These were calculated for $4 \AA$ units of the $\{111\}$ thin film ${ }^{14}$ except the surface and subsurface layers (data is presented for each individual layer). Results for $1500 \mathrm{~K}$ are presented in figure 6 with further results given in the supplementary 
information. The magnitude of the surface diffusion coefficients is consistent with the total diffusion coefficients. That is the magnitude decreases with the quantity of $\mathrm{Gd}^{3+}$ doping (except for the $\mathrm{MnO}$ substrate at $1500 \mathrm{k}$ ) and $D_{2 d}$ is greatest for the $\mathrm{FeO}$ substrate. From equation 1 one would expect that the diffusion would reflect the number of oxygen vacancies and this is clearly not the case.

All the results are characterised by lowest values of $D_{2 d}$ close to the interface. Importantly, this includes configurations in which the $\mathrm{Gd}^{3+}$ and $\mathrm{O}^{2-}$ ions are randomly distributed through the material. The value of the diffusion coefficients gradually increases away from the interface reaching a maximum at approximately 10 to $20 \AA$. It does not reflect the number of $\mathrm{O}^{2-}$ or vacancies, for example there is a dip in the number of oxygen atoms (or increase in the number of vacancies) in the first sub-interface and second sub-interface layers approximately $4 \AA$ from the interface. This change in oxygen ion (vacancy) concentration is not reflected in the calculated values of $D_{2 d}$. The maximum in the diffusion at approximately 10 to $20 \AA$ from the interface often corresponds to the lowest concentration of vacancies. The values for $D_{2 d}$ are lower in the centre of the thin film for the randomly distributed $\mathrm{Gd}^{3+}$ configurations.

The most notable difference between the randomly and Monte Carlo generated distributions of $\mathrm{Gd}^{3+}$ ions exists for $\mathrm{O}^{2-}$ ion diffusion at and close to the surface. After the maximum at the centre of the thin film the diffusion coefficients for the random distributions remain approximately constant (see supplementary information) to within approximately $5 \AA$ of the surface. Here the values of $D_{2 d}$ increase to a maximum at the surface and this is assumed to result from a change in the elastic properties allowing the oxygen ions to move more freely. Similar behaviour has been observed for yttrium doped ceria surfaces. ${ }^{14}$ This is in contrast to the MC generated configurations where the value of the $D_{2 d}$ decreases towards the surface. Only for the subsurface oxygen, where there is a greater number of vacancies, is a marked increase in the value of $D_{2 d}$. Then there is a further decrease at the surface. The spike in the value tends to decrease in the order $x=0.1>x=$ $0.2>x=0.3$ and is the inverse of the number of vacancies (see figure 6). This suggests that the space charge layer created by $\mathrm{Gd}^{3+}$ and $\mathrm{O}^{2-}$ ions reduces the oxygen ion conductivity at the surface. 


\section{Discussion and Conclusion.}

The Hybrid Monte Carlo method has been employed to determine the distribution of ions within Gd doped ceria thin films. This technique has been combined with molecular dynamics simulations to evaluate the rôle of both lattice strain and segregation on oxygen ion diffusion to inform the design of solid oxide fuel cells. The calculated activation energies for oxygen ion diffusion are in excellent agreement with experiment. ${ }^{47,48,49}$ The greatest values for the $\mathrm{O}^{2-}$ ion diffusion coefficients was determined for thin films with $10 \% \mathrm{Gd}^{3+}$ ion concentration rather than a maximum at 20 to $30 \%$ for bulk materials. This observation is consistent with experimental results. ${ }^{50}$ Comparison of the diffusion coefficients with those calculated with a random distribution of dopant cations indicates that the influence of dopant-vacancy association is negligible and the thin films will not suffer from ageing in a similar manner to bulk materials. ${ }^{5,46}$

The Monte Carlo simulations indicate that a tensile strain of 2 to 3 percent has little influence on the degree of segregation of dopant cations to both surfaces and interfaces. Only when the strain results in the formation of dislocations is there any significant change in segregation. Unfortunately, the fracturing of the thin film reduces the oxygen ion mobility and the diffusion coefficients for the entire thin film are influenced more strongly by the strain rather than segregation. Thus our calculation do not support the hypothesis that the amount of segregation can be controlled via the strain in the thin film. ${ }^{16,17}$ Approximately a 1.5 increase in the $\mathrm{O}^{2-}$ ion diffusion coefficient is observed for the thin films in this study and can be attributed to the reduction in activation energy from the strain in the lattice rather than significant change in the segregation behaviour of $\mathrm{Gd}^{3+}$ ions.

This paper reports the distribution of $\mathrm{Gd}^{3+}$ ions, $\mathrm{O}^{2-}$ ions and vacancies as a function of distance from the substrate/thin film interface for the thin films on $\mathrm{MgO}$ and $\mathrm{FeO}$ substrates. The distribution of these ions is consistent with the formation of a space charge layer at both the interface and surface. However, the interaction of the space charge layers with the change in elastic environment of atoms at the interface and surface and how this influences the $\mathrm{O}^{2-}$ transport is complex. Let us first consider the nature and diffusion at the interface. The interface has the greatest segregation of $\mathrm{Gd}^{3+}$ ions yet has the lowest $\mathrm{O}^{2-}$ ion diffusion. In addition, the values of $D_{2 d}$ are very similar for the configurations in which the 
$\mathrm{Gd}^{3+}$ and $\mathrm{Ce}^{4+}$ ions are randomly distributed. This suggests that the structure of the interface and the mobility of the $\mathrm{O}^{2-}$ ions is largely controlled by the elastic properties of the interface. This is despite an elevated number of $\mathrm{O}^{2-}$ ion vacancies in the sub-interface layers that indicates as the formation of a weak space charge layer. The central portion of the thin film (approximately $15 \AA$ above the interface) tends to have the greatest oxygen ion diffusion coefficients despite the lowest number of oxygen vacancies. The greatest difference in $D_{2 d}$ values is observed at the surface (within $5 \AA$ of the surface plane). Where the $\mathrm{Gd}^{3+}$ ions are randomly distributed the $\mathrm{O}^{2-}$ ion diffusion coefficients remain roughly constant and then increase at the surface. A similar profile was observed in yttrium doped ceria surfaces. ${ }^{14}$ In contrast, for $\mathrm{Gd}^{3+}$ ion configurations obtained from Monte Carlo calculations (i.e. a space charge layer has been created) the $\mathrm{O}^{2-}$ diffusion coefficients decrease and a spike in the value of $D_{2 d}$ is observed for the subsurface layer. These calculations indicate that the space charge layer modifies the rate of oxygen diffusion at the surface and center of the thin films in this study. However, the elastic environment is the main factor that determines the rate of diffusion at the interface. There remains considerable scope for deriving alternate interfaces for segregation in solid solutions of oxides, including the segregation to the layers immediately under the surface layer. Our Monte Carlo method is general and we shall apply this in future work to more complex interfaces of technological importance.

\section{Acknowledgements.}

The EPSRC grant EP/K016288/1 for funding and the Hartree Centre, Daresbury Laboratory, for access to the Scafell Pike computer. 
Tables

\begin{tabular}{|l|l|l|}
\hline Substrate & $x$ direction & $y$ direction \\
\hline $\mathrm{MgO}$ & +0.7 & -0.03 \\
\hline $\mathrm{FeO}$ & +3.2 & +2.5 \\
\hline $\mathrm{MnO}$ & +6.1 & +5.0 \\
\hline
\end{tabular}

Table 1. The percentage difference in the lattice parameters of $\mathrm{CeO}_{2}$ relative to those of the substrate. The table is for $\mathrm{O} \mathrm{K}$, however, both temperature and $\mathrm{Gd}$ doping have little influence on the degree of mismatch (see text for further discussion). The area of the interface is approximately $3700 \AA^{2}$. Note negative and positive values indicate compression and tension respectively.

\begin{tabular}{|l|l|l|l|}
\hline \multicolumn{5}{|c|}{ MgO substrate } \\
\hline composition & $1000 \mathrm{~K}$ & $1500 \mathrm{~K}$ & $2000 \mathrm{~K}$ \\
\hline Int. $x=0.1$ & 0.37 & 0.36 & 0.35 \\
\hline Int. $x=0.2$ & 0.56 & 0.53 & 0.53 \\
\hline Int. $x=0.3$ & 0.58 & 0.58 & 0.59 \\
\hline Cen. $x=0.1$ & 0.04 & 0.03 & 0.03 \\
\hline Cen. $x=0.1$ & 0.13 & 0.12 & 0.11 \\
\hline Cen. $x=0.1$ & 0.24 & 0.25 & 0.23 \\
\hline Srf. $x=0.1$ & 0.27 & 0.29 & 0.28 \\
\hline Srf. $x=0.2$ & 0.39 & 0.40 & 0.42 \\
\hline Srf. $x=0.3$ & 0.47 & 0.44 & 0.46 \\
\hline & & FeO substrate & \\
\hline Int. $x=0.1$ & 0.32 & 0.32 & 0.34 \\
\hline Int. $x=0.2$ & 0.51 & 0.50 & 0.49 \\
\hline Int. $x=0.3$ & 0.57 & 0.53 & 0.56 \\
\hline Cen. $x=0.1$ & 0.05 & 0.05 & 0.05 \\
\hline Cen. $x=0.1$ & 0.14 & 0.13 & 0.12 \\
\hline Cen. $x=0.1$ & 0.22 & 0.22 & 0.21 \\
\hline Srf. $x=0.1$ & 0.24 & 0.24 & 0.23 \\
\hline Srf. $x=0.2$ & 0.42 & 0.41 & 0.41 \\
\hline Srf. $x=0.3$ & 0.51 & 0.49 & 0.45 \\
\hline
\end{tabular}

Table 2. The fraction of $\mathrm{Gd}^{3+}$ ions in $\mathrm{CeO}_{2}$ thin films that have been placed on a $\mathrm{MgO}$ and FeO substrates. Int denotes the $\mathrm{Gd}^{3+}$ fraction at the thin film / substrate interface, Cen an average of the four central cation layers and $S r f$ the $\mathrm{Gd}^{3+}$ fraction at the surface. Note data for the $\mathrm{MnO}$ substrate is not presented as it is impossible to allocate $\mathrm{Ce}^{4+}$ and $\mathrm{Gd}^{3+}$ to a specific layer. 


\begin{tabular}{|c|c|c|c|}
\hline & $1000 \mathrm{~K}$ & $1500 \mathrm{~K}$ & $2000 \mathrm{~K}$ \\
\hline \multicolumn{4}{|c|}{$\mathrm{MgO}$ substrate } \\
\hline MCR $x=0.1$ & 1.38 & 17.97 & 72.15 \\
\hline MCR $x=0.2$ & 0.48 & 12.90 & 73.57 \\
\hline MCR $x=0.3$ & 0.25 & 6.61 & 52.64 \\
\hline $\operatorname{Ran} x=0.1$ & 1.46 & 17.03 & 65.99 \\
\hline $\operatorname{Ran} x=0.2$ & 0.74 & 11.94 & 67.74 \\
\hline $\operatorname{Ran} x=0.3$ & 0.41 & 7.14 & 53.36 \\
\hline \multicolumn{4}{|c|}{ FeO substrate } \\
\hline MCR $x=0.1$ & 2.46 & 31.58 & 112.67 \\
\hline MCR $x=0.2$ & 0.87 & 19.75 & 106.55 \\
\hline $\operatorname{MCR} x=0.3$ & 0.34 & 10.40 & 79.32 \\
\hline $\operatorname{Ran} x=0.1$ & 2.86 & 32.53 & 114.18 \\
\hline $\operatorname{Ran} x=0.2$ & 1.72 & 20.97 & 106.53 \\
\hline $\operatorname{Ran} x=0.3$ & 0.82 & 12.68 & 87.76 \\
\hline \multicolumn{4}{|c|}{ MnO substrate } \\
\hline MCR $x=0.1$ & 1.09 & 15.17 & 66.63 \\
\hline MCR $x=0.2$ & 0.63 & 12.61 & 69.77 \\
\hline MCR $x=0.3$ & 0.27 & 7.30 & 57.35 \\
\hline $\operatorname{Ran} x=0.1$ & 1.20 & 16.02 & 67.28 \\
\hline $\operatorname{Ran} x=0.2$ & 1.08 & 13.10 & 75.81 \\
\hline $\operatorname{Ran} x=0.3$ & 0.60 & 7.75 & 63.09 \\
\hline
\end{tabular}

Table 3. The diffusion constants, $10^{-8} \mathrm{~cm}^{2} / \mathrm{s}$, of $\mathrm{O}^{2-}$ ions in $\mathrm{CeO}_{2}$ that have been placed on $\mathrm{MgO}, \mathrm{FeO}$ and $\mathrm{MnO}$ substrates. MCR denotes that the thin film structure has been generated using the Monte Carlo simulations and Ran for a random distribution of $\mathrm{Gd}^{3+}$ and $\mathrm{Ce}^{4+}$ ions. Note the diffusion of $\mathrm{O}^{2-}$ ions in the substrate has been excluded. 


\begin{tabular}{|l|l|}
\hline \multicolumn{2}{|c|}{ MgO substrate } \\
\hline MCR $x=0.1$ & $0.68(0.01)$ \\
\hline MCR $x=0.2$ & $0.87(0.01)$ \\
\hline MCR $x=0.3$ & $0.91(0.05)$ \\
\hline \multicolumn{2}{|c|}{ FeO substrate } \\
\hline MCR $x=0.1$ & $0.66(0.005)$ \\
\hline MCR $x=0.2$ & $0.83(0.01)$ \\
\hline MCR $x=0.3$ & $0.93(0.05)$ \\
\hline \multicolumn{2}{|c|}{ MnO substrate } \\
\hline MCR $x=0.1$ & $0.71(0.02)$ \\
\hline MCR $x=0.2$ & $0.80(0.03)$ \\
\hline MCR $x=0.3$ & $0.91(0.05)$ \\
\hline
\end{tabular}

Table 4. The calculated activation energies in eV for the $\mathrm{O}^{2-}$ diffusion in $\mathrm{CeO}_{2}$ thin films on $\mathrm{MgO}, \mathrm{FeO}$ and $\mathrm{MnO}$ substrates (the size of the error bar is given in the parentheses). MCR denotes that the thin film structure has been generated using the Monte Carlo simulations. Note the diffusion of $\mathrm{O}^{2-}$ ions in the substrate has been excluded. 
Figures.

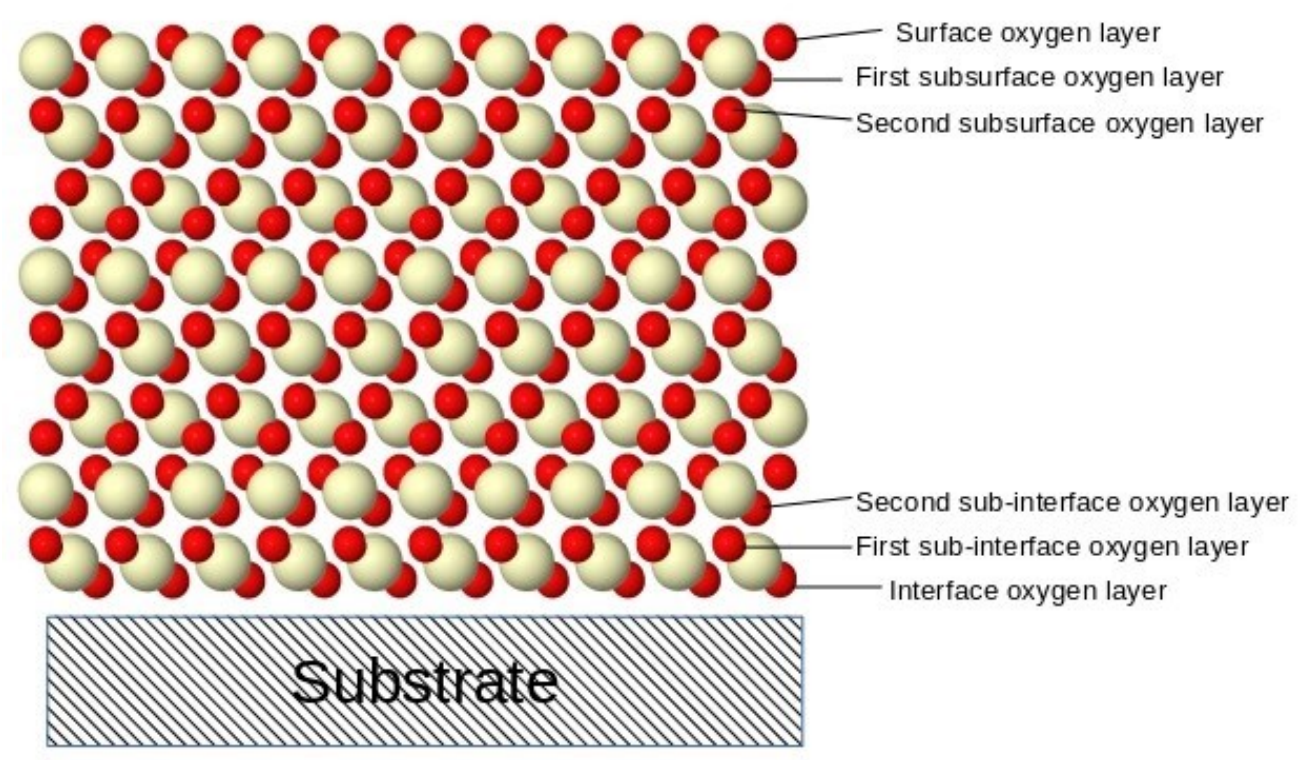

Figure 1. Side view of the $\mathrm{CeO}_{2}\{111\}$ surface to illustrate the three planes in the repeat unit of the surface. The terminology used within the text to describe the oxygen layers at the surface and interface is also demonstrated. Colour scheme for the atoms: $\mathrm{O}^{2-}$ red and $\mathrm{Ce}^{4+}$ light brown. NOTE this cell was not used in the calculations, but is provided to demonstrate the surface structure and terminology used to describe the oxygen layers. 

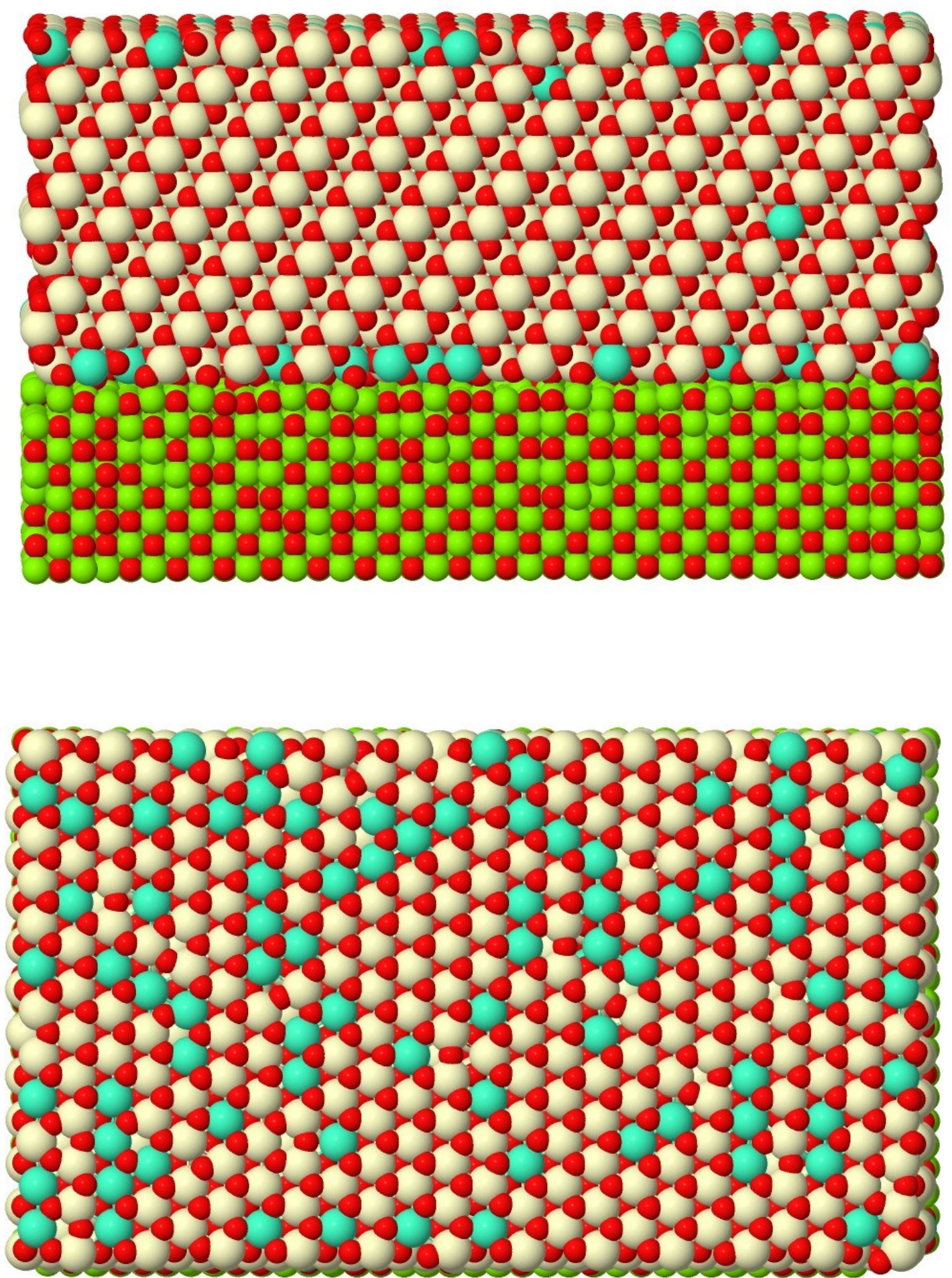

Figure 2. Side and top view of $\mathrm{CeO}_{2}$ supported on $\mathrm{MgO}$ substrate. The snapshot of the configuration is obtained from the Monte Carlo simulations at $1000 \mathrm{~K}$ where 10 percent of the $\mathrm{Ce}^{4+}$ ions have been replaced with $\mathrm{Gd}^{3+}$ ions. Only the region 1 ions are displayed for the $\mathrm{MgO}$ substrate. Colour scheme for the atoms: O red, Ce light brown, $\mathrm{Gd}$ light blue and Mg green. 

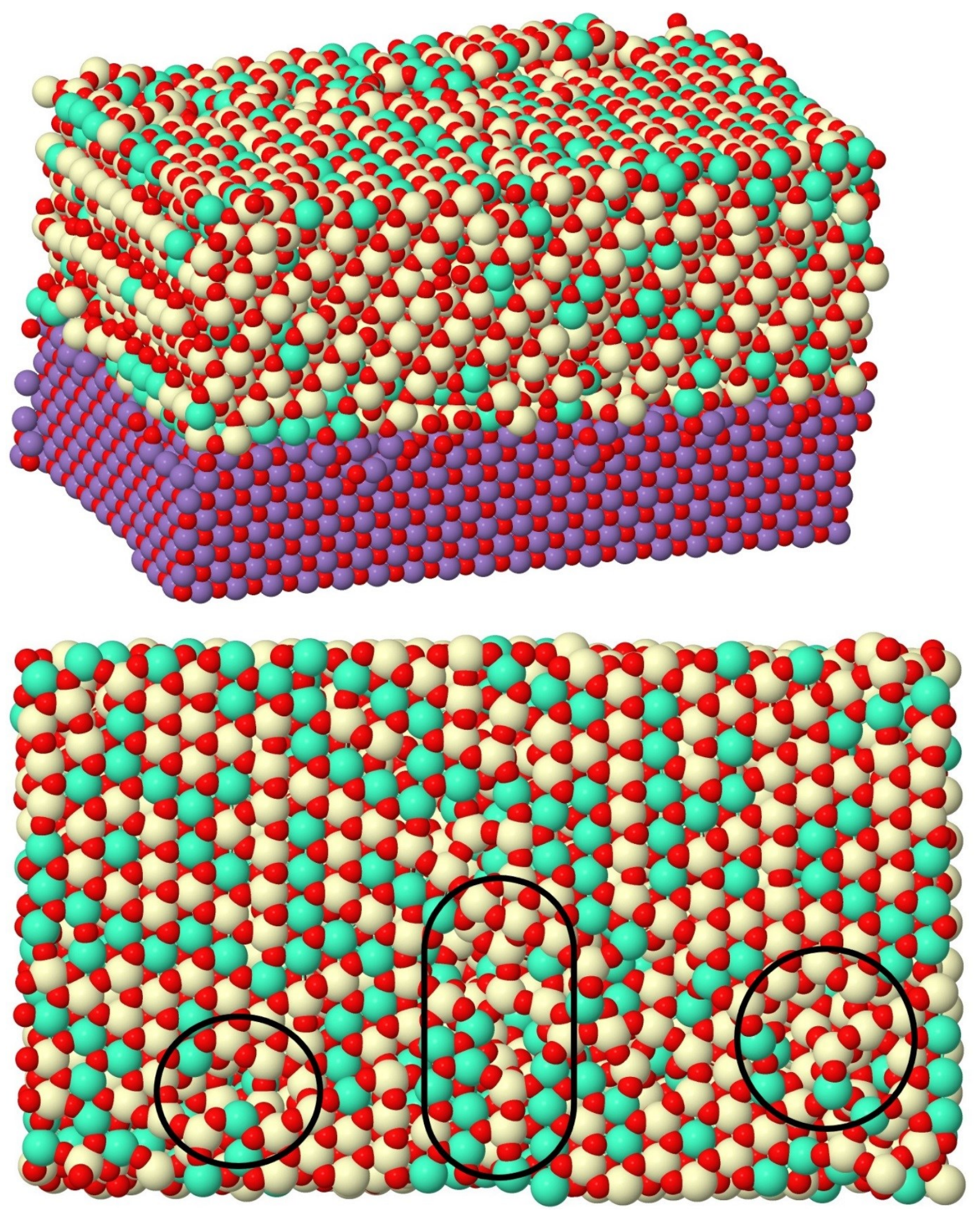

Figure 3. Side and top view of $\mathrm{CeO}_{2}$ supported on $\mathrm{MnO}$ substrate to demonstrate the formation of dislocations in the thin film. The snapshot of the configuration is obtained from the Monte Carlo simulations at $1500 \mathrm{~K}$ where 30 percent of the $\mathrm{Ce}^{4+}$ ions have been replaced with $\mathrm{Gd}^{3+}$. Colour scheme for the atoms: $\mathrm{O}$ red, Ce light brown, $\mathrm{Gd}$ light blue and $\mathrm{Mn}$ purple. Regions where dislocations have formed in the thin film are indicated by black ellipsoids. 


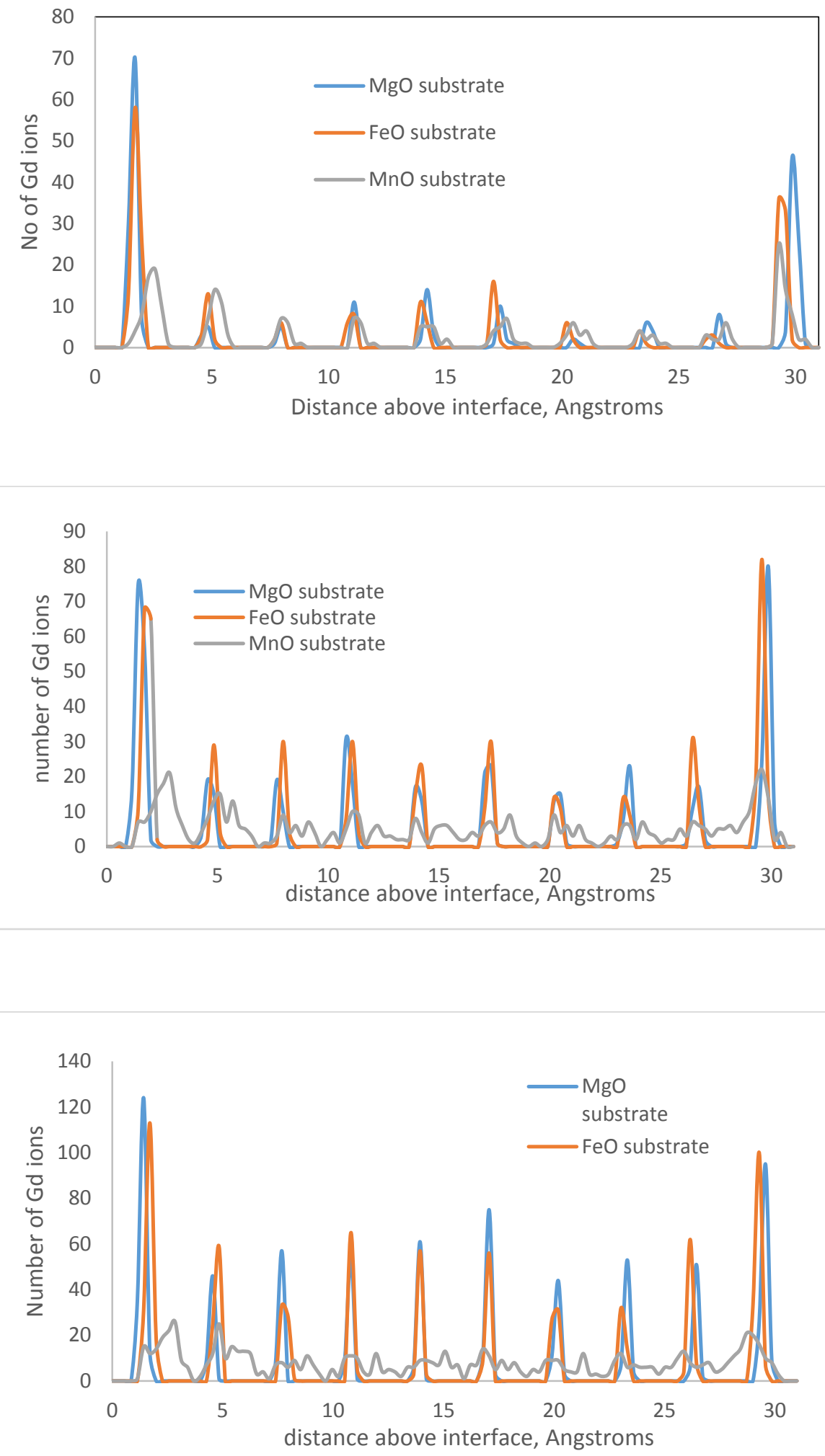
Figure 4. The $\mathrm{Gd}^{3+}$ concentration as a function of depth for thin films grown on $\mathrm{MgO}, \mathrm{FeO}$ and $\mathrm{MnO}$ substrates. The figure is for simulations undertaken at $1000 \mathrm{~K}$ and with concentrations $\mathrm{Gd}^{3+}$ ions of (a) $x=0.1$, (b) $x=0.2$ and (c) $x=0.3$. The number of $\mathrm{Gd}^{3+}$ ions was sampled with the a spacing of the bins of $0.25 \AA$. 

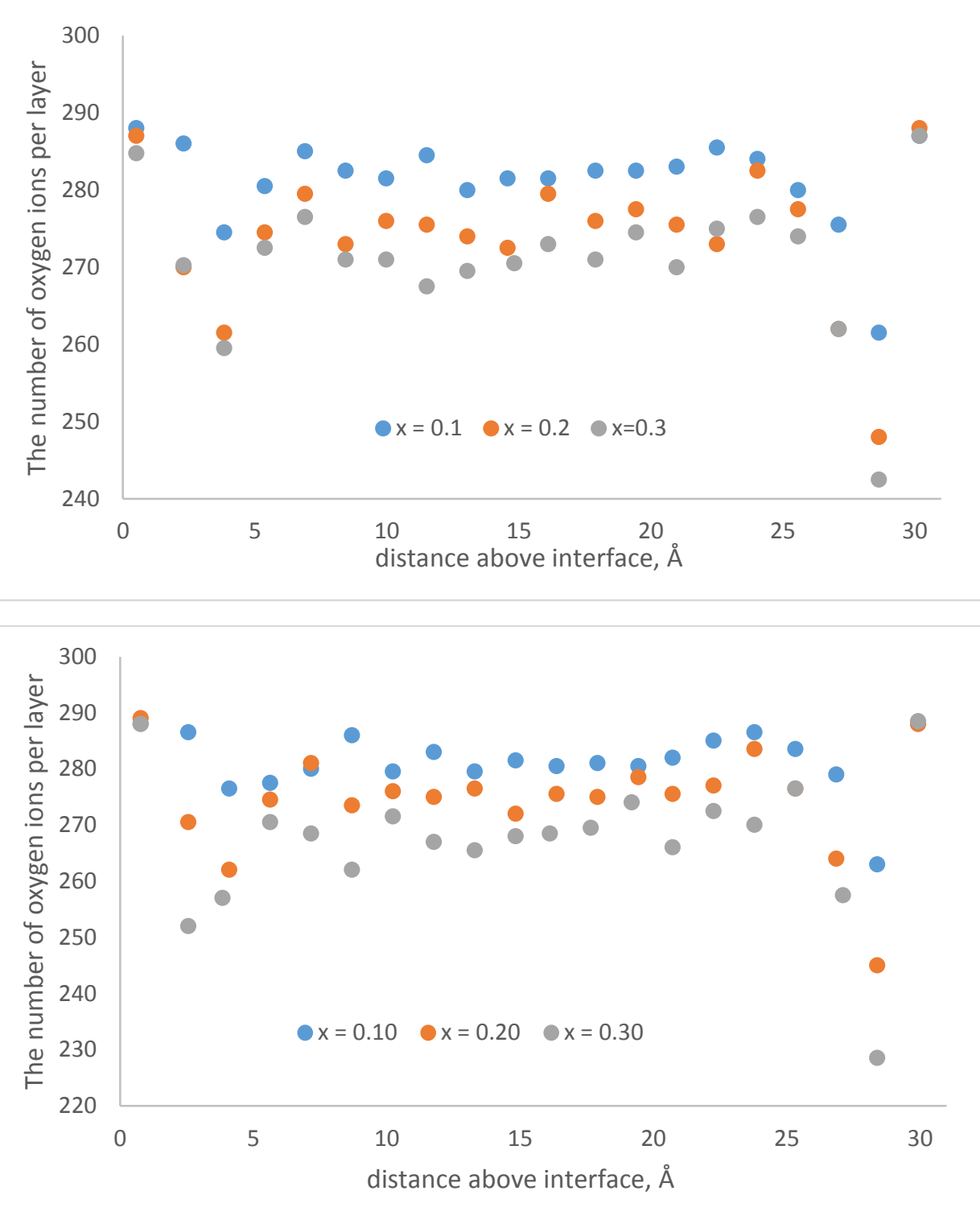

Figure 5. The number of $\mathrm{O}^{2-}$ ions per layer in $\mathrm{CeO}_{2}$ thin films on (a) $\mathrm{MgO}$ and (b) $\mathrm{FeO}$ substrates. The results are for simulations at $1500 \mathrm{~K}$ with concentrations of $\mathrm{Gd}^{3+}$ ions of $x=$ $0.1, x=0.2$ and $x=0.3$. 

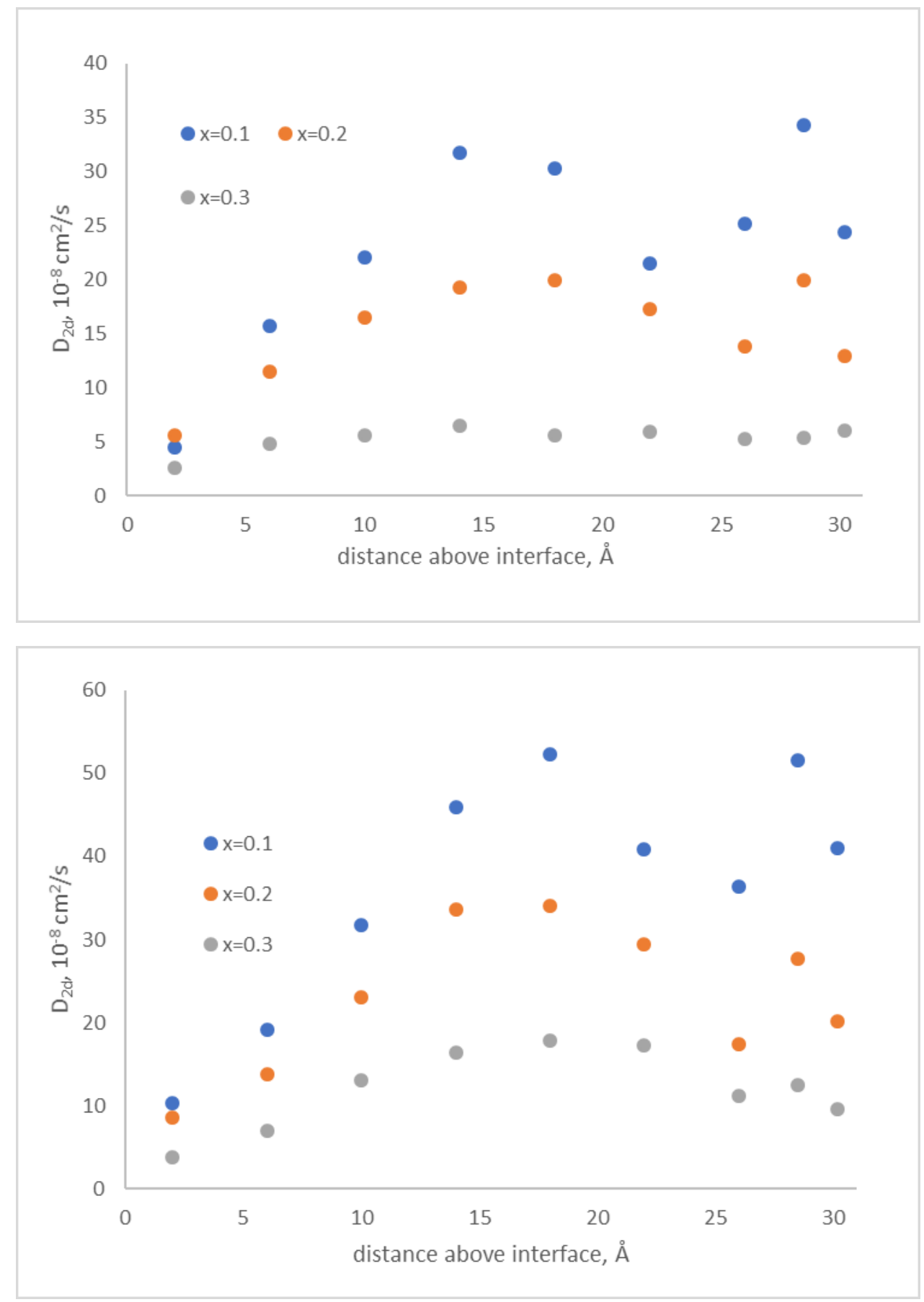


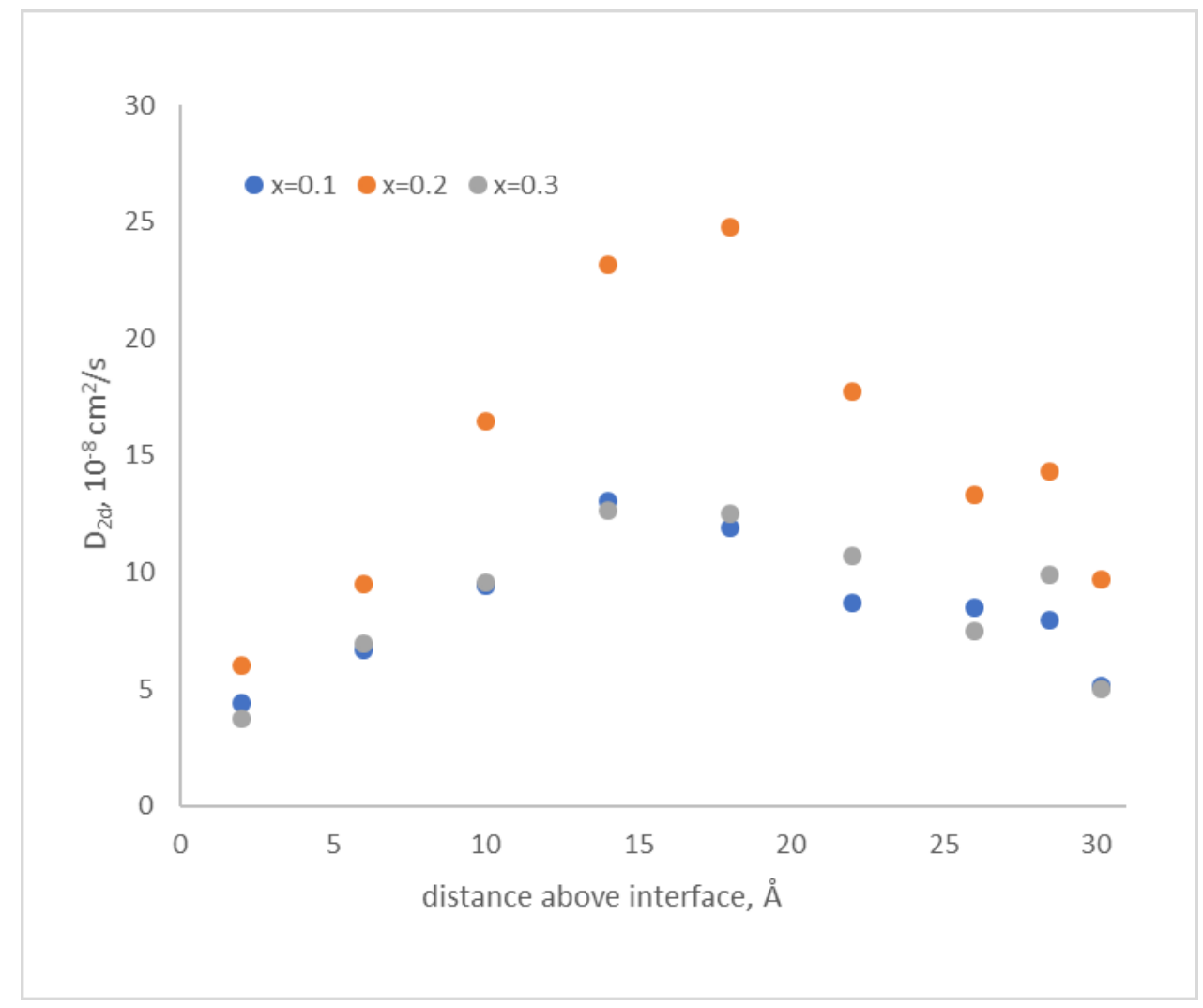

Figure 6. The two dimensional $\mathrm{O}^{2-}$ diffusion coefficient, $D_{2 d}$, plotted as a function of the distance above the interface. Results are presented for the (a) $\mathrm{MgO}$, (b) FeO and (c) $\mathrm{MnO}$ substrates and simulations undertaken at $1500 \mathrm{~K}$. Further results are in the supplementary information. 


\section{References}

${ }^{1}$ J. Koettgen, S. Grieshamer, P. Hein, B.O. Grope, M. Nakayama and M. Martin, 2018, 20, 14291-14321.

${ }^{2}$ S.J. Skinner, S.J. and J.A. Kilner, Materials Today, 2003, 6, 30-37.

${ }^{3}$ M. Mogensen, Solid State Ionics, 2000, 129, 63-94.

${ }^{4}$ D.S. Mebane and R.A De Souza, Energy Environ. Sci., 2015, 8, 2935-2940.

${ }^{5}$ T.S. Zhang J. Ma, L.B. Kong, S.H. Chan and J.A. Kilner, Solid State Ionics, 2004, 170, 209-217.

${ }^{6}$ J. Garcia-Barriocanal, A. Rivera-Calzada, M. Varela, Z. Sefrioui, E. Iborra, C. Leon, S. J. Pennycook and J. Santamaria, Science, 2008, 321, 676-680

${ }^{7}$ I. Kosacki, C. M. Rouleau, P. F. Becher, J. Bentley and D. H. Lowndes, Solid State Ionics, 2005, 176, 1319-1326.

${ }^{8}$ M. Sillassen, P. Eklund, N. Pryds, E. Johnson, U. Helmersson and J. B $\emptyset$ ttiger, Adv. Funct. Mater., 2010, 20, 2071-2076.

${ }^{9}$ T. Suzuki, I. Kosacki and H.U. Anderson, Solid State Ionics, 2002, 151, 111-121.

${ }^{10}$ H. Huang, T.M. Gur, Y. Saito and F. Prinz, Appl. Phys. Lett., 2006, 89, 143107.

${ }^{11}$ A. Kushima and B. Yildiz, J. Mater. Chem., 2010, 20, 4809-4819.

${ }^{12}$ R. A. de Souza, A. Ramadan and S. Hörner, Energy Environ. Sci., 2012, 5, 5445-5453.

${ }^{13}$ M.J.D. Rushton, A. Chroneos, S.J. Skinner, J.A. Kilner, R.W. Grimes, Solid State Ionics, 2013, 230, 37-42.

${ }^{14}$ M. Burbano, D. Marrocchelli and G.W. Watson, J. Electroceram., 2014, 32, 28-36.

${ }^{15}$ M. J. D. Rushton and A. Chroneos, Scientific Reports, 2014, 4, 6068.

${ }^{16}$ G. F. Harrington, A. Cavallaro, D. W. McComb, S. J. Skinner, and J. A. Kilner, Phys. Chem. Chem. Phys., 2017, 19, 14319-14336.

${ }^{17}$ G. F. Harrington, S. J. Skinner and J. A. Kilner, J. Am. Ceram. Soc., 2018, 101, 1310-1322.

${ }^{18}$ A. E. Hughes, J. Am. Ceram. Soc., 1995, 78, 369-378.

${ }^{19}$ M. de Ridder, R. G. van Welzenis, A. W. Denier van der Gon and H. H. Brongersma, J. Appl. Phys., 2002, 92, 3056-3064.

${ }^{20}$ D. R. Mullins, Surface Science Reports, 2015, 70, 42-85.

${ }^{21}$ J. A. Purton, M. Y. Lavrentiev, N. L. Allan and I. T. Todorov, Phys. Chem. Chem. Phys., 2005, 7, 3601-3604.

22 J. A. Purton and N. L Allan, J. Cryst. Growth, 2006, 294, 130-136.

${ }^{23}$ H. Nörenberg and G. Briggs, Surf. Sci., 1999, 424, L352

${ }^{24}$ M. Nolan, S.C. Parker, G.W. Watson, Surf. Sci., 2005, 595, 223-232.

${ }^{25}$ P. W. Tasker, J. Phys. C - Solid State Phys., 1979, 12, 4977-4984.

${ }^{26}$ H. A. Aleksandrov, I. Z. Koleva, K. M. Neyman, T. T. Tabakova and G. N. Vayssilov, RSC Adv., 2018, 8, 33728-33741.

${ }^{27}$ P. W. Tasker, J. Phys. C - Solid State Phys., 2001, 12, 4977-4984.

${ }^{28}$ C. R. A. Catlow and W. C. Mackrodt, Computer Simulation of Solids, 1982, SpringerVerlag,Berlin.

${ }^{29}$ J. A. Purton, G. Barrera, N. L. Allan and J. D. Blundy, J. Phys. Chem.B, 1998, 102, 52025207.

${ }^{30}$ M. Y. Lavrentiev, N. L. Allan, G. D. Barrera and J. A. Purton, J. Phys. Chem. B, 2001, 105, 3594-3599.

31 J. Purton, J. Crabtree and S. C. Parker, Mol. Sim., 2013, 39, 1240-1252. 
${ }^{32}$ N. Metropolis, A.W. Rosenbluth, M.N. Rosenbluth, A.H. Teller and E. Teller, J. Chem. Phys., 1953, 21, 1087-1092.

${ }^{33}$ E. Bitzek, P. Koskinen, F. Gahler, M. Moseler and P. Gumbsch, Phys. Rev. Lett., 2006, 97, 170201-170204.

34 J. Purton, N. L. Allan and D. S. D. Gunn, Solid State lonics, 2017, 299, 32-37.

${ }^{35}$ D. S. D. Gunn, J. A. Purton and S. Metz, Solid State lonics, 2018, 324, 128-137.

${ }^{36}$ M. P. Allen and D. J. Tildesley, Computer Simulation of Liquids, Oxford University Press, 2017.

${ }^{37}$ L. Minervini, M. O. Zacate, R. W. Grimes, Solid State lonics, 1999, 116, 339-349.

${ }^{38}$ D. Wolf, P. Keblinski, S.R. Philpot and J. Eggebrecht, J. Chem. Phys., 1999, 110, 8255-8282.

${ }^{39}$ C.J. Fennell and J.D. Gezelter, J. Chem. Phys., 2006, 124, 234104.

${ }^{40}$ P. Demontis, S. Spanu and G. B. Suffritti, J. Chem. Phys., 2001, 114, 7980-7988.

${ }^{41}$ J. A. Purton and N. L. Allan, Comp. Mater. Sci., 2015, 103, 244-249.

${ }^{42}$ X. Aparicio-Angés, A. Roldan and N. H. de Leeuw, Chem. Mater., 2015, 27, 7910-7917.

${ }^{43}$ E. E. Helgee, A. Lindman and G. Wahnström\}, Fuel Cells, 2013, 13, 19-28.

${ }^{44}$ D. S. Mebane and R. A. De Souza, Energy Environ. Sci., 2015, 8, 2935-2940.

${ }^{45}$ A. F. Zurhelle, X. Tone, A. Klein, D. S. Mebane and R. A. De Souza, Angew. Chem. Int. Ed., 2017, 56, 14516-14520.

${ }^{46}$ J. A. Purton, A. Archer, D. S. D. Gunn and N. L. Allan, J. Mat. Chem. A, 2016, 12, 4592-4602.

${ }^{47}$ T. Suzuki, I. Kosacki and H.U. Anderson, Solid State Ionics, 2002, 151, 111-121.

${ }^{48}$ H. Huang, T.M. Gur, Y. Saito and F. Prinz, Appl. Phys. Lett., 2006, 89, 143107

${ }^{49}$ M. C. Göbel, G. Gregori, X. Guo and J. Maier, Physical Chemistry Chemical Physics, 2010, 12, 14351-14361.

${ }^{50}$ D. K. Hohnke, Solid State Ionics, 1981, 5, 531-534 

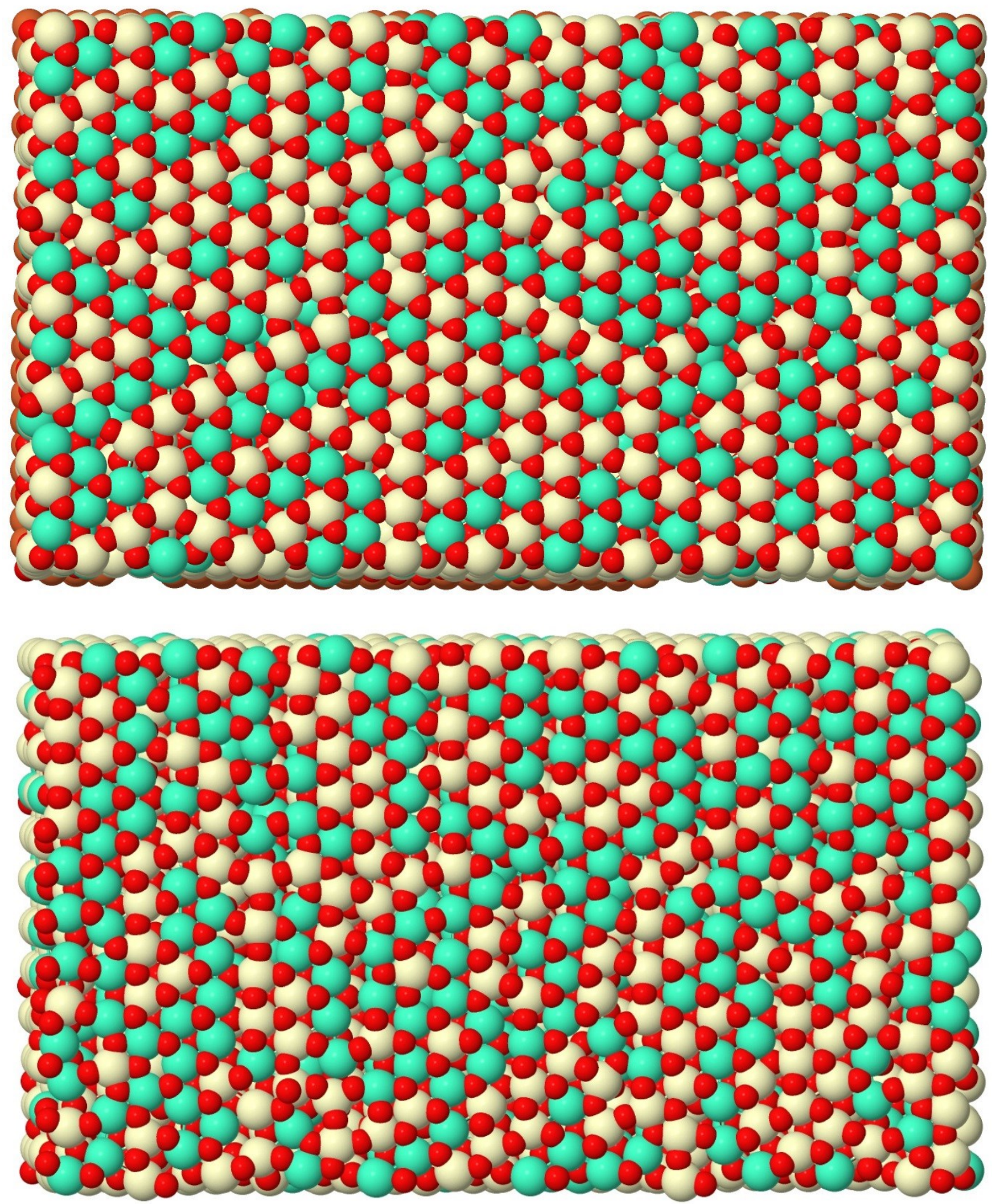

Figure 1. Top and bottom view of $\mathrm{CeO}_{2}$ supported on $\mathrm{FeO}$ substrate. The snapshot of the configuration is obtained from the Monte Carlo simulations at $1500 \mathrm{~K}$ where 30 percent of the $\mathrm{Ce}^{4+}$ ions have been replaced with $\mathrm{Gd}^{3+}$. In the bottom view the $\mathrm{FeO}$ substrate has been removed. Colour scheme for the atoms: $O$ red, Ce light brown and Gd light blue. 

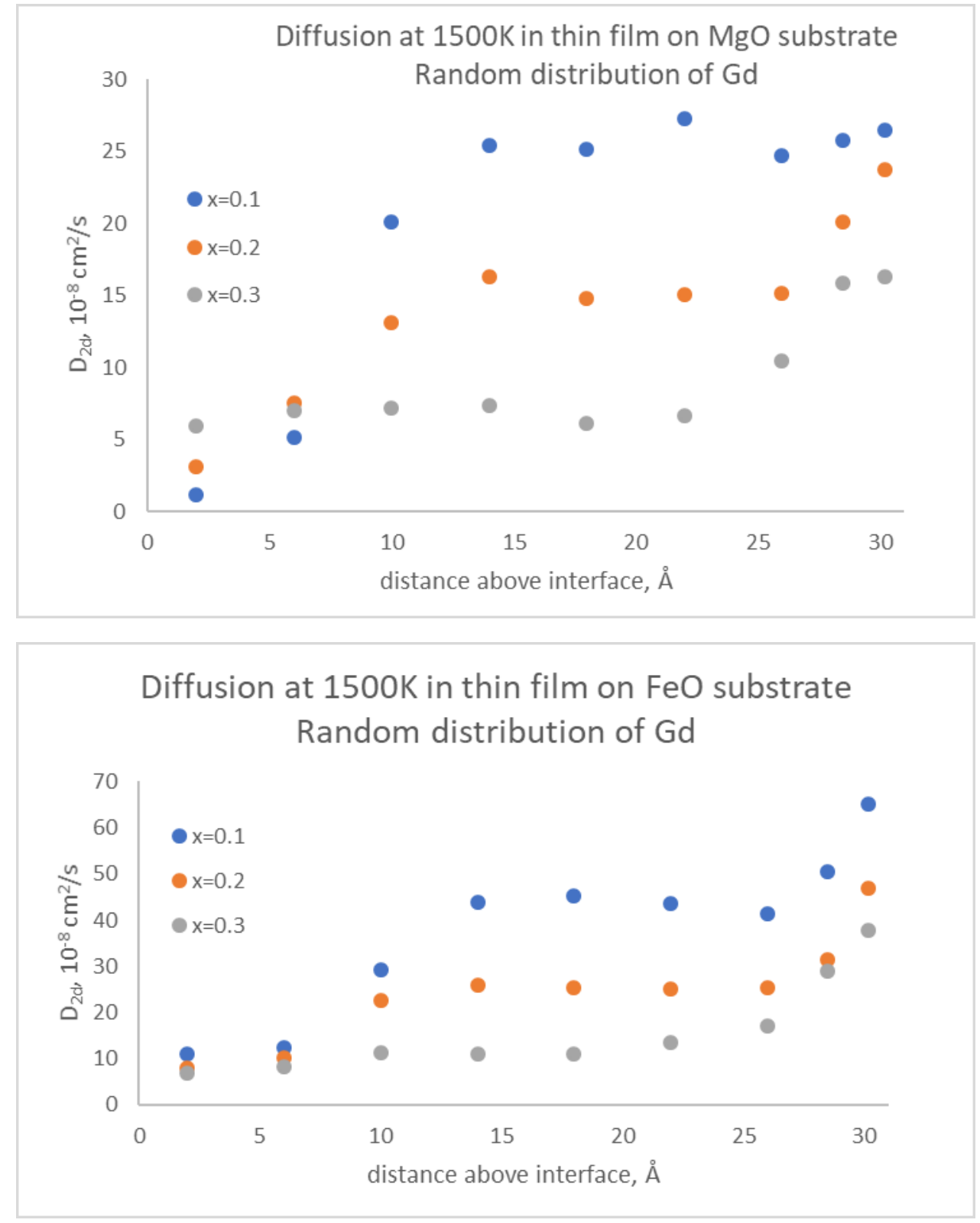

Figure 2. The diffusion coefficient for $\mathrm{O}^{2-}$ diffusion parallel to the surface plane as function of distance from the interface for thin films grown on $\mathrm{MgO}$ and $\mathrm{FeO}$ substrates. The figure is for simulations undertaken at $1500 \mathrm{~K}$ where the $\mathrm{Gd}^{3+}$ ions are randomly distributed. 

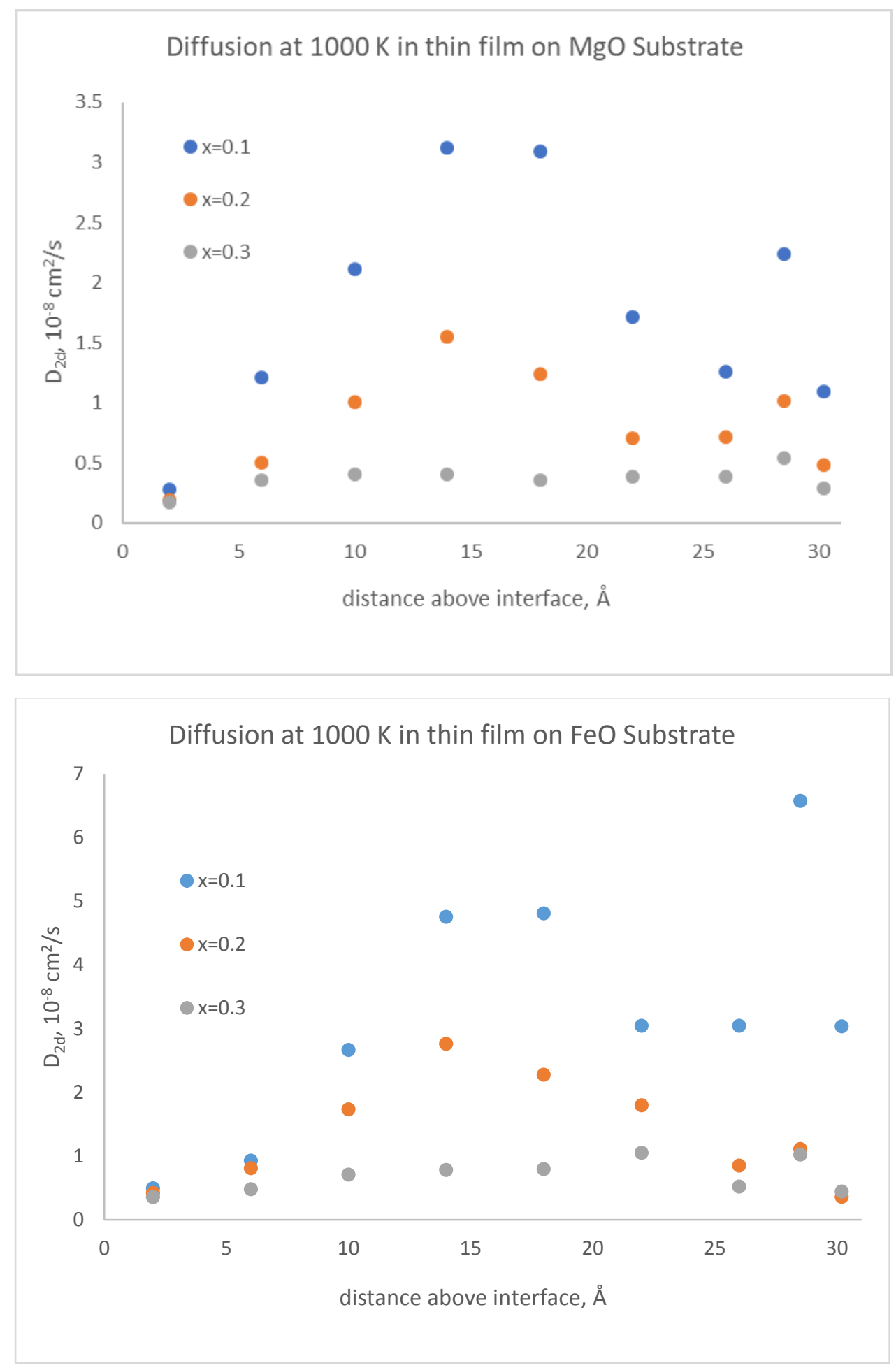


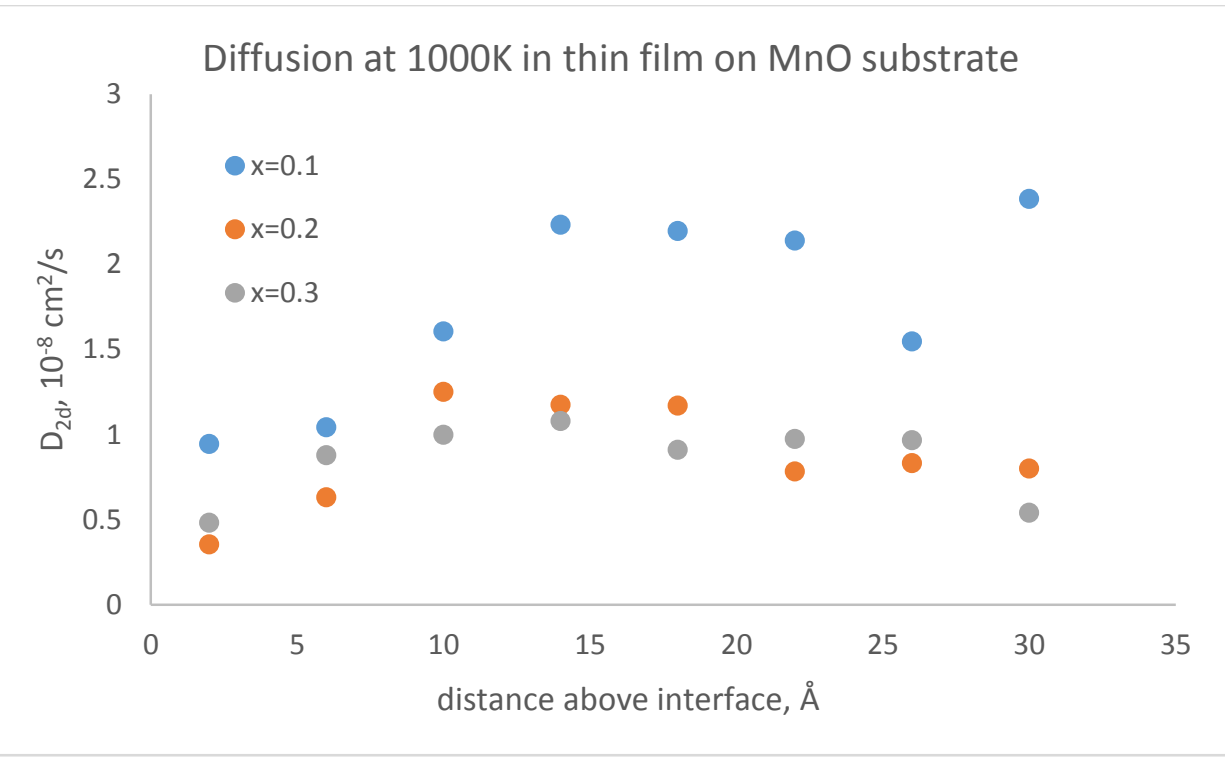

Figure 3. The $\mathrm{O}^{2-}$ diffusion coefficient parallel to the surface plane as a function of distance from the interface for thin films placed on $\mathrm{MgO}, \mathrm{FeO}$ and $\mathrm{MnO}$ substrates. The simulations were undertaken at $1000 \mathrm{~K}$ and the thin film structures were taken from Monte Carlo calculations. 



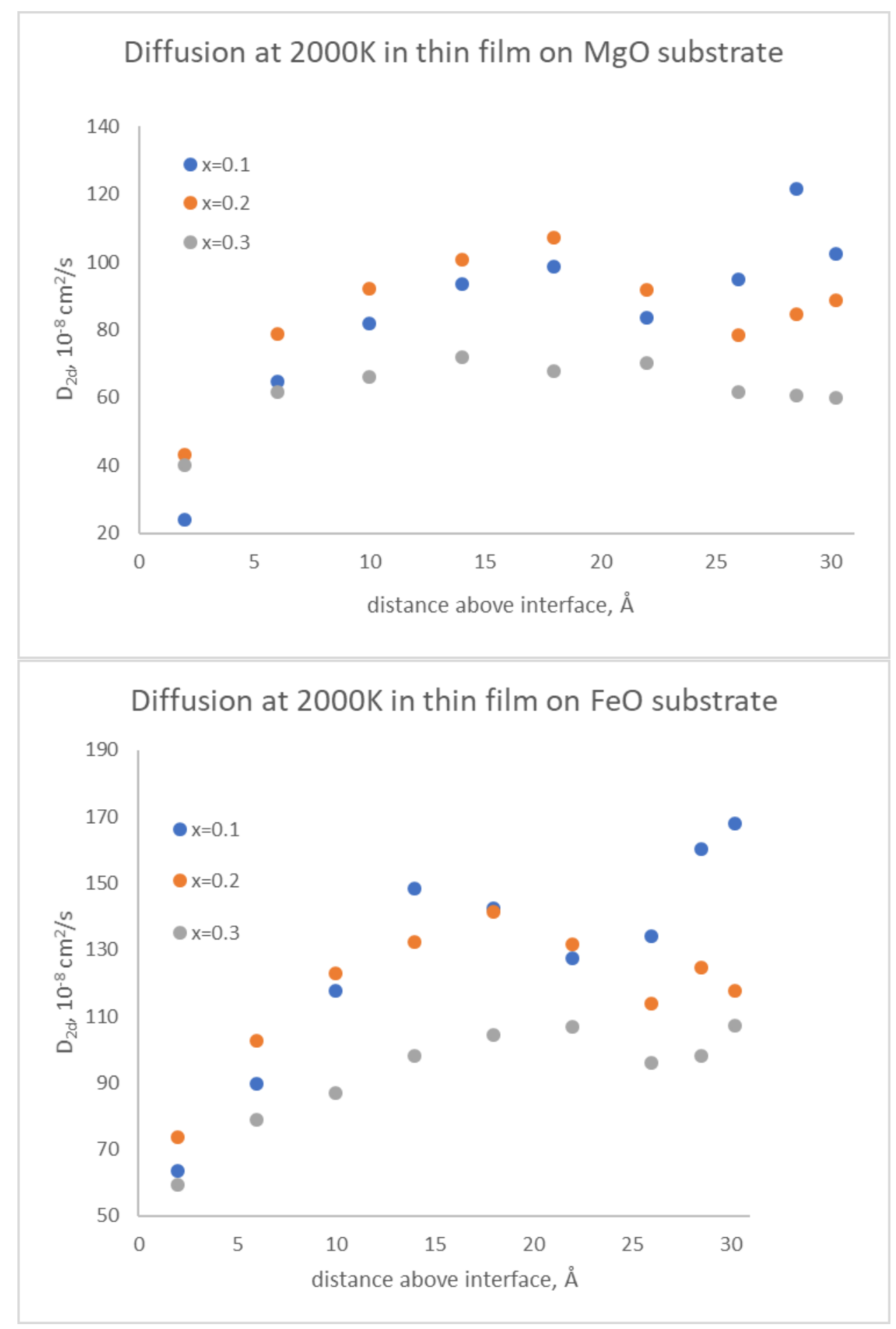




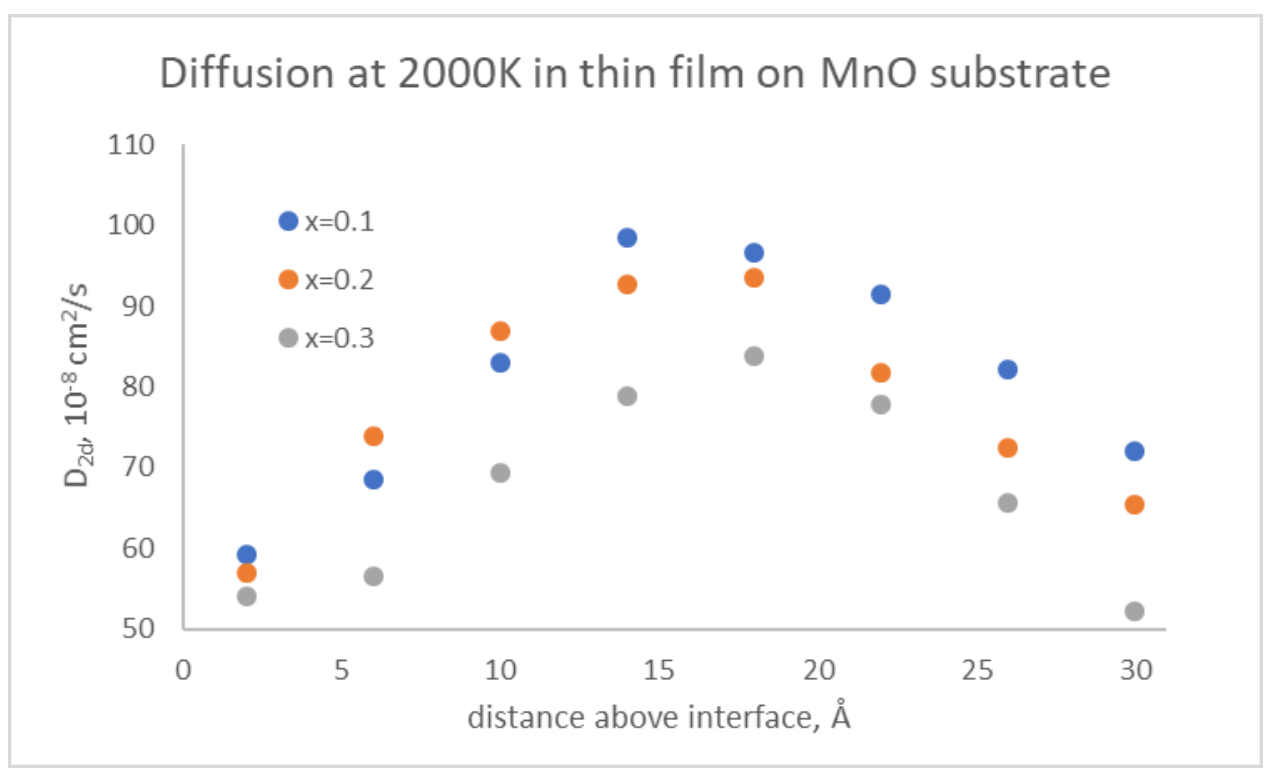

Figure 4. The $\mathrm{O}^{2-}$ diffusion coefficient parallel to the surface plane as a function of distance from the interface for thin films placed on $\mathrm{MgO}, \mathrm{FeO}$ and $\mathrm{MnO}$ substrates. The simulations were undertaken at $2000 \mathrm{~K}$ and the thin film structures were taken from Monte Carlo calculations. 